Portland State University

PDXScholar

Civil and Environmental Engineering Faculty

Publications and Presentations

6-6-2018

\title{
Minimum Required Length for Geotechnical Lateral Stability of RockSocketed Pile Shafts
}

Arash Khosravifar

Portland State University, karash@pdx.edu

Zia Zafir

Kleinfelder

Follow this and additional works at: https://pdxscholar.library.pdx.edu/cengin_fac

Part of the Civil and Environmental Engineering Commons Let us know how access to this document benefits you.

\section{Citation Details}

Khosravifar, Arash and Zafir, Zia, "Minimum Required Length for Geotechnical Lateral Stability of RockSocketed Pile Shafts" (2018). Civil and Environmental Engineering Faculty Publications and Presentations. 446.

https://pdxscholar.library.pdx.edu/cengin_fac/446

This Post-Print is brought to you for free and open access. It has been accepted for inclusion in Civil and Environmental Engineering Faculty Publications and Presentations by an authorized administrator of PDXScholar. Please contact us if we can make this document more accessible: pdxscholar@pdx.edu. 


\title{
Minimum Required Length for Geotechnical Lateral Stability of Rock- Socketed Pile Shafts
}

\author{
Arash Khosravifar, Ph.D., P.E. M.ASCE ${ }^{1}$ and Zia Zafir, Ph.D., P.E., G.E. ${ }^{2}$ \\ ${ }^{1}$ Department of Civil and Environmental Engineering, Portland State University, 1930 SW $4^{\text {th }}$ \\ Ave. Portland, OR 97201; e-mail: karash@pdx.edu \\ ${ }^{2}$ Kleinfelder, 2882 Prospect Park Drive Suite 200, Rancho Cordova, CA 95670; e-mail: \\ zzafir@kleinfelder.com
}

\begin{abstract}
The original strong-rock (SR) p-y curves for rock-socketed shafts exhibit a brittle response where the post-peak resistance drops to approximately zero. This brittle response could result in a progressive failure of the rock p-y curves which, in turn, results in excessive pile lengths. This paper proposes a modification to the strong-rock (SR) p-y curves where the post-peak residual strength is equal to $20 \%$ of the ultimate resistance $\left(0.2^{*}\right.$ pult $)$. This residual resistance is proposed based on the assumption that the lateral resistance of cracked rock (after the peak point) should not be smaller than the lateral resistance of heavily weathered rock estimated from the weak-rock (WR) and Liang et al. p-y curves. The effectiveness of the modified SR curves is evaluated against the results of a lateral load test. The modified SR curves are compared against back-calculated py curves from the lateral load test.
\end{abstract}

\section{INTRODUCTION}

Rock-socketed pile shafts are an effective choice of bridge foundations in areas with shallow bedrock. They provide large skin friction to carry axial loads. Their lateral response, however, needs to be better studied. One of the main issues in the design of rock-socketed shafts pertains to the choice of p-y springs in rocks. Several types of p-y curves have been proposed for rock, e.g. Strong-Rock curves (Vuggy Limestone) in LPILE (Ensoft 2014), Weak-Rock curves (Reese 1997), and fractured rock mass curves by Liang et al. (2009) (implemented as Massive Rock in LPILE). The degree of complexity and the number of input parameters vary in the above mentioned p-y criteria. This study focuses on the strong-rock (SR) curves as they require the least number of input parameters to be defined and may be considered as an alternative for more complex p-y criteria in sensitivity analyses.

The strong-rock (SR) p-y curves show a brittle response for the rock mass with significant postpeak reduction of lateral resistance at very small displacements ( $\sim .24 \%$ of rock-socket diameter). 
Figure 1 shows the brittle fracture of the original strong-rock (SR) p-y curve. If the pile displacement at soil/rock interface exceeds the above threshold, a progressive failure (or unzipping) of p-y curves may trigger in the top several meters of rock until pile displacements fall below this threshold. This observation was noted in NCHRP Synthesis 360 (Turner 2006) which concluded that the level of displacements in many practical situations exceed the displacements associated with the brittle response (i.e. 0.0024 times the shaft diameter). The NCHRP Synthesis 360 concluded that some practitioner, choose to use the Weak-Rock criteria over the Strong-Rock criteria to avoid the brittle response issue. This often becomes problematic when the geotechnical lateral stability of piles is being analyzed where the Strength Limit State resistance factors are used. This analysis is often referred to as the "minimum required length for lateral stability" in AASHTO (2014) and the FHWA manual for the design of drilled shafts (Brown et al. 2010). The 'un-zipping' of p-y curves in strong-rock could result in excessively long rock-socket lengths that are controlled by the minimum required length for lateral stability (sometimes as high as 5-pile diameter). However, rock socket lengths greater than 2-3 diameters lead to additional costs and pose a greater construction risk. There is no evidence that brittle failure and socket 'un-zipping', as predicted using the existing SR p-y curves, actually occurs. It follows that longer than necessary sockets are not warranted on the basis of strong rock p-y analysis alone. This could happen in areas with high seismicity or cases where liquefaction-induced lateral spreading exerts considerable lateral loads on a pile.

Figure 2 shows an example lateral response of a 2.1-m diameter RC pile shaft socketed in a strong rock $(\mathrm{SR})$ with uniaxial compressive strength $(\mathrm{Qu})$ of $8 \mathrm{MPa}$ and rock quality designation (RQD) of $100 \%$. This example pile was a foundation concept for a bridge project in a highly seismic area. The required rock-socket length for axial loads was estimated to be 6 meters ( 2.8 diameters). However, the minimum required rock-socket length for lateral stability was estimated 8 meters ( 3.8 diameters). Such long embedment poses constructability issues which could compromise the structural performance of the pile. In addition to the unreasonably long required rock-socket length, the pile head deflection is excessively large too (i.e. $\sim 18 \mathrm{~cm}$ ), which is an artifact of the progressive fracture (un-zipping) of strong-rock (SR) p-y curves.

This paper provides a solution for the brittle response of the strong-rock (SR) p-y springs by proposing a more reasonable residual strength based on the resistance that is expected from a heavily weathered rock at large deflections. The proposed modification will be described in the

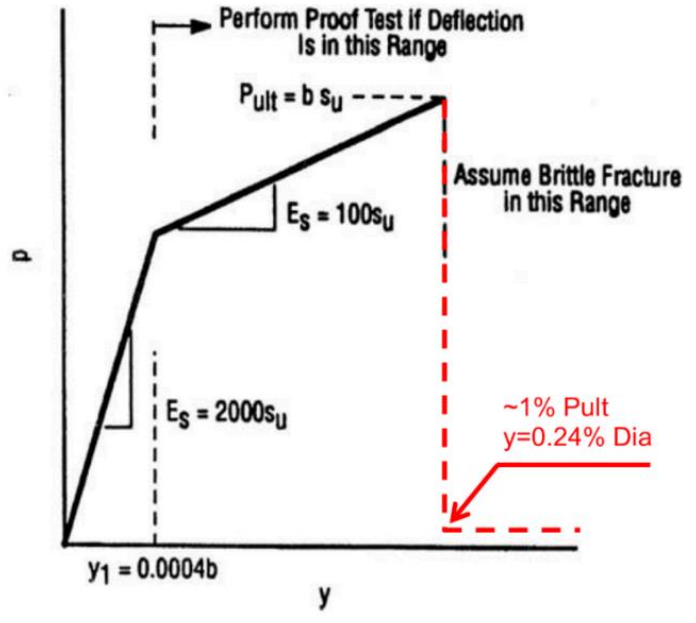

Figure 1. The original strong-rock (SR) p-y curve implemented in LPILE (modified from Ensoft 2014) 
next section. The modified p-y curves will be compared against other commonly used rock springs and advantages and disadvantages will be discussed. The performance of the modified p-y curves is evaluated against the results of a lateral load test on a rock-socketed shaft.

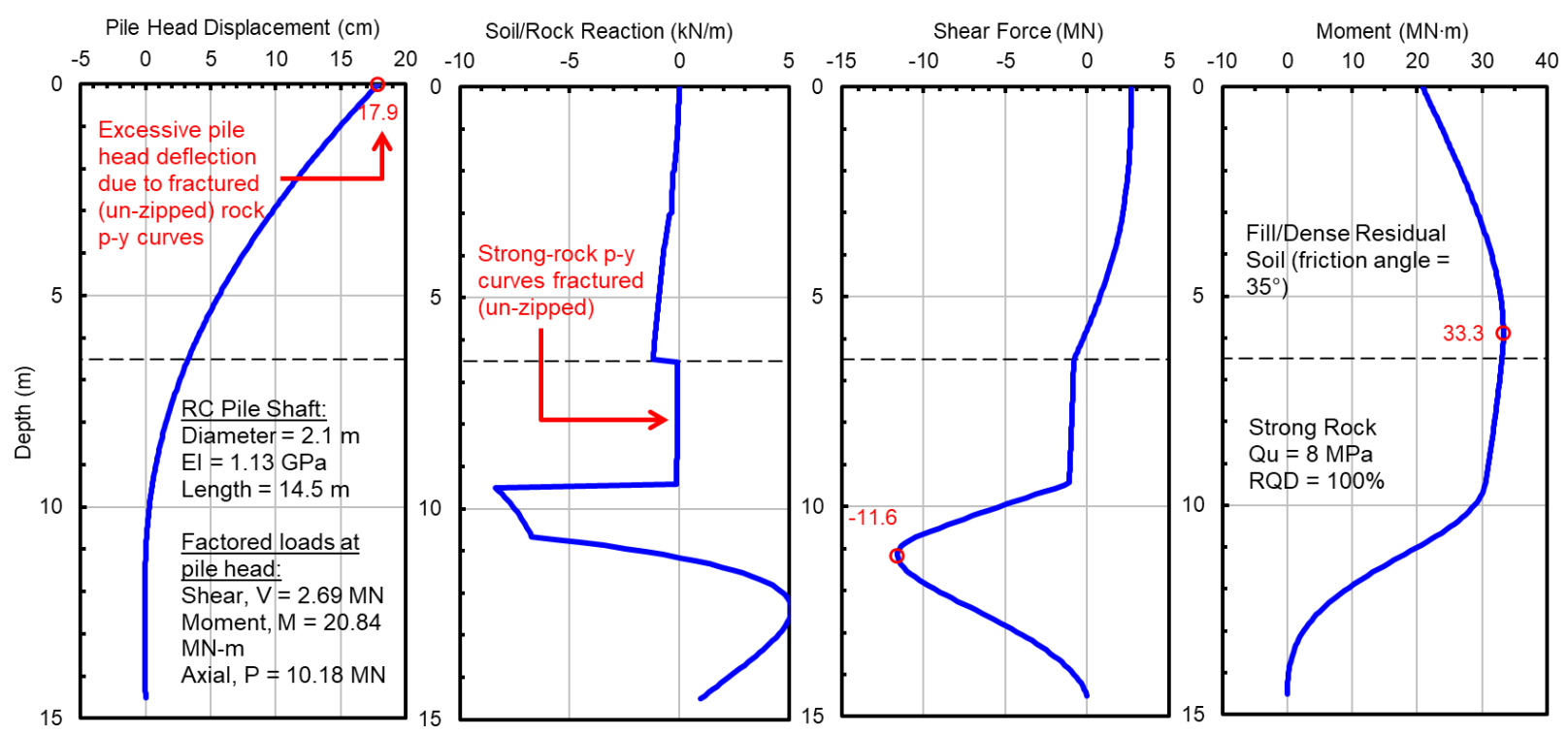

Figure 2. An example of brittle fracture (un-zipping) of strong-rock (SR) p-y curves for a 2.1-m diameter RC pile subjected to shear and moment at pile head.

\section{PROPOSED SOLUTION}

Modified Strong-Rock (SR) P-Y Curve. A simple and practical solution is proposed here to avoid the progressive failure (or un-zipping) that is experienced in the strong-rock (SR) p-y curves for displacements greater than $0.24 \%$ diameter $(0.0024 * \mathrm{D})$. This solution is based on the hypothesis that the post-peak residual strength of the SR p-y curve should not be smaller than the resistance obtained from the weak-rock (WR) p-y curve at similar displacements. The rationale is that after rock mass cracks, its shear strength drops to the value that would be expected from a heavily fractured rock mass. Unfortunately, there are not many lateral load tests where the piles were pushed enough to cause deflections greater than $0.24 \%$ diameter at the rock elevation. Future experimental studies are needed to objectively test the above hypothesis.

Figure 3a shows a strong-rock (SR) p-y curve for a rock with an intact uniaxial compressive strength $\mathrm{Qu}=8 \mathrm{MPa}$ (similar to the example in Figure 2). Also shown on this figure is the weakrock (WR) p-y curve. The ultimate rock reaction in WR was calculated based on a uniaxial compressive strength $\mathrm{Qu}=1.6 \mathrm{MPa}$ (reduced from an intact rock $\mathrm{Qu}$ of $8 \mathrm{MPa}$ by a reduction factor of 0.2 to account for rock mass fracturing). The ultimate rock reaction ( $p_{\text {ult }}$ ) in WR is depth dependent, that is pult increases by a factor of 5 from rock surface to a depth of 3 diameters, beyond which pult remains constant. Therefore, it was important to extract the WR curve at a representative 
depth. Sensitivity analysis on a limited number of cases showed that the thickness of the strongrock that cracks under Strength Limit State loads is about one pile diameter (the thickness of the un-zipped area in Figure 2). Therefore, the WR curve plotted on Figure 3a was extracted from the mid depth of the cracked rock, i.e. 0.5 diameter (or $1.05 \mathrm{~m}$ for a $2.1-\mathrm{m}$ diameter pile). The initial stiffness of the WR curves is defined based on the initial modulus of rock mass ( $\mathrm{E}_{\mathrm{ir}}$ ) which was estimated to be equal to $350^{*} \mathrm{Qu}$ following the recommendations of Deere (1968) and using the reduced $\mathrm{Qu}$ for fractured rock (i.e. $\mathrm{E}_{\mathrm{ir}}=567 \mathrm{MPa}$ ). The transition from the linear segment to the ultimate strength of the WR curve is defined by $\mathrm{K}_{\mathrm{rm}}$. A typical value of 0.0005 was used for $\mathrm{K}_{\mathrm{rm}}$ in this study.

In addition, the rock p-y curve by Liang et al. (2009) is plotted on Figure 3a. This curve was developed for a uniaxial compressive strength of intact rock $\mathrm{Qu}=8 \mathrm{MPa}$, Material Index mi $=8$, Geologic Strength Index GSI $=30$ and the Poisson's ratio $v=0.3$ based on the recommendations of Hoek (2001) for a "very poor quality rock mass". The Liang et al. curves are also depth dependent; therefore, similar to WR, the Liang et al. curve on Figure 3 was developed for a depth equal to 0.5 diameter from the rock surface.

The following conclusions can be drawn from comparing different rock p-y curves on Figure 3a: The brittle drop to zero in the original SR is too conservative as both WR and Liang et al. curves show considerable rock resistances at deformations greater than $0.24 \%$ diameter. Therefore, the modified SR curve is proposed to have a non-zero residual strength that is conservatively equal to the average of WR curve at large displacements. This value was estimated to be approximately $20 \%$ of pult of the SR curve. It will be shown next that using this non-zero residual strength eliminates the need for unreasonably long piles to fulfill the geotechnical lateral stability requirement. It is also observed that the SR curve provide an average estimation of the initial stiffness compared to other curves plotted on the figure, i.e. the initial portion of the WR curve is almost vertical and the initial stiffness of the Liang et al. curve is much softer than the SR curve. This is advantageous in seismic studies where the foundation stiffness is used to estimate seismic demands.

Figure $3 \mathrm{~b}$ shows the modified strong-rock (SR) p-y curves for uniaxial compressive strength $\mathrm{Qu}=$ $8 \mathrm{MPa}, 3.9 \mathrm{MPa}$, and 1.6 $\mathrm{MPa}$, corresponding to $\mathrm{RQD}=100 \%, 60 \%$, and $25 \%$. The reduction factors that were used in this study to modify the intact rock Qu to account for fracturing were calculated using $\alpha^{2}$, where $\alpha$ is the joint modification factor obtained from O'Neill and Reese (1999). However, other field tests or empirical equations can be used too to estimate uniaxial compressive strength of rock mass of various degrees of fracturing (e.g. Marinos and Hoek 2000, and Liang et al. 2009)

Effects on Minimum Required Length for Lateral Stability. Figure 4 shows the effectiveness of the proposed modification to the SR springs by comparing the minimum required length for 
lateral stability for the example pile shown on Figure 2. The rock was modeled using the original SR curve as well as the modified SR curve. This figure shows the pile head deflection versus pile length. The pile length beyond which lateral deflection ceases to increase is usually picked as the minimum required length for lateral stability. The rock is at 6.5-meter depth. The case with the original SR results in 8 meters of rock-socket (3.8 diameters) which is unnecessarily long and causes constructability issues. The case using the modified SR (with the residual strength equal to $20 \%$ of pult) results in 5.5 meter of rock socket (2.6 diameter) which is a more constructible and economical foundation.
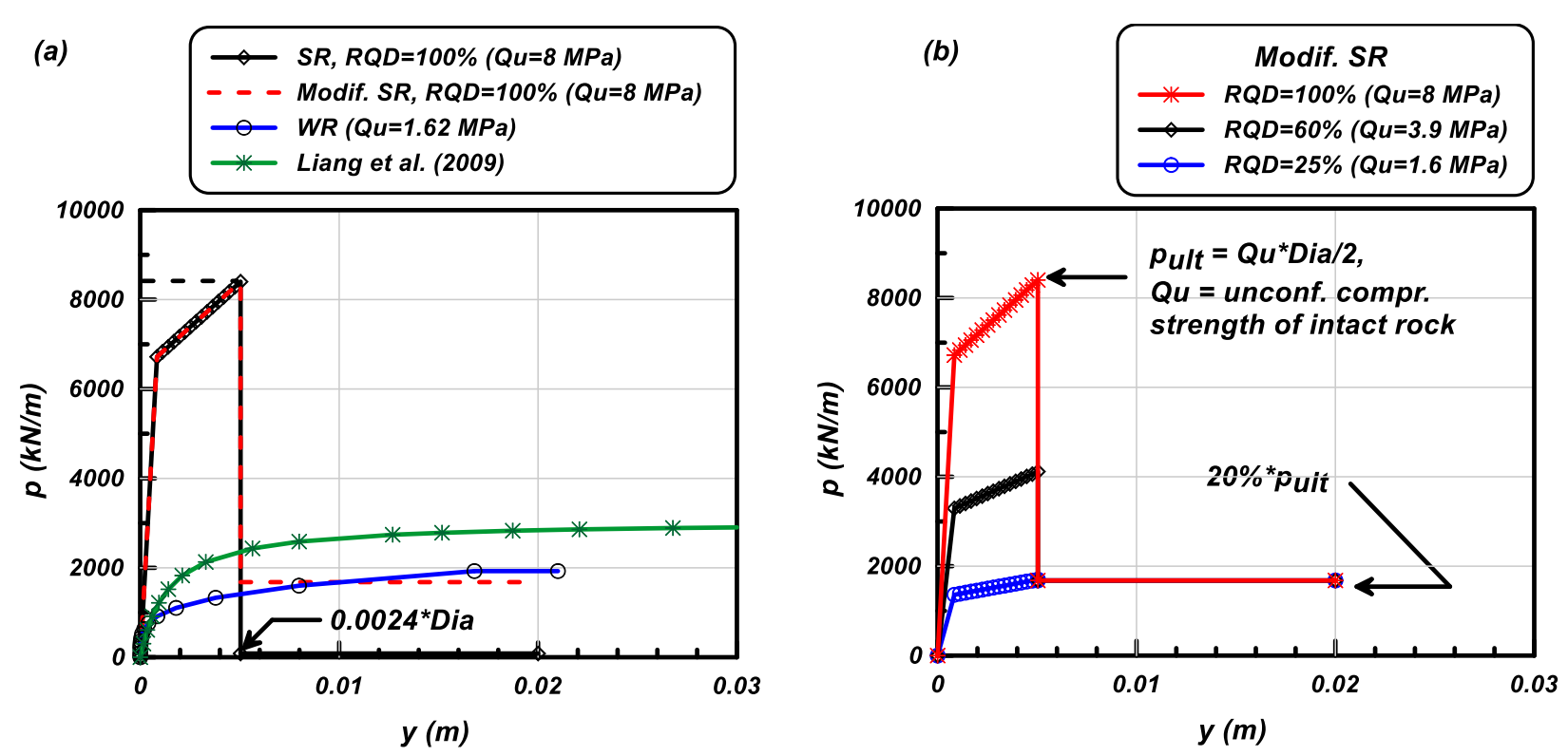

Figure 3. (a) Modified strong-rock (SR) curve and comparison with original SR, WR and Liang et al. (2009) curves, and (b) modified strong-rock (SR) curves for rock with various degrees of RQD.

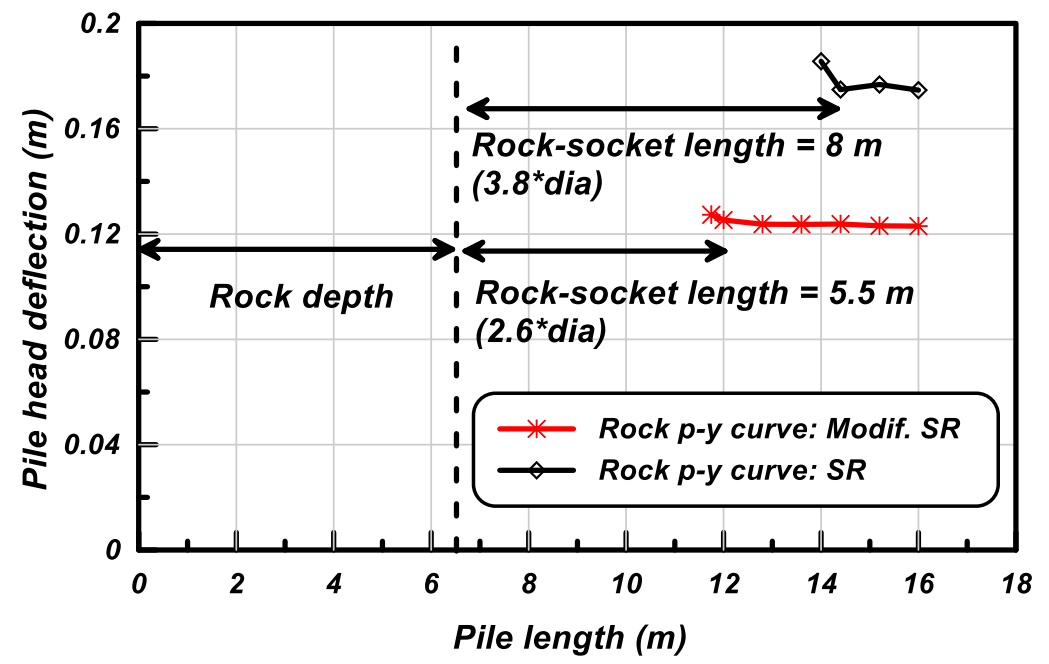

Figure 4: Minimum required length for lateral stability using SR and the modified SR as p-y springs for rock 


\section{COMPARISON AGAINST LATERAL LOAD TEST}

To assess the performance of the modified SR curves in capturing key behaviors of lateral pile response, a lateral load test was modeled in LPILE. The lateral load-deformation response, and pile moment and displacement profiles were estimated using a p-y model and were compared against measured data.

Lateral Load Test on a Rock-Socketed Pile Shaft. The lateral load test was performed on a 6foot diameter Reinforced Concrete (RC) pile shaft socketed in Siltstone (Schnabel 2014). A permanent steel casing with 0.625 -inch thickness was used in the top 7.5 feet of soil. The rocksocket was 19.5 feet long. The lateral load was applied at pile head up to 1126 kips. The pile head was free-against rotation. No axial load was applied on the shaft. Strain gauges were used to measure strains along the reinforcing bars. An inclinometer was used to measure the displacement profile along the pile. The uniaxial compressive strength $(\mathrm{Qu})$ of the intact rock, averaged over the length of the rock socket, was 6409 psi. The rock quality along the rock socket consisted of 3 feet of fractured rock with rock quality designation (RQD) of $25 \%$, overlying 5 feet of fractured rock with RQD of $60 \%$, overlying sound rock with RQD of 90 to $100 \%$.

P-y Model. A p-y model was generated in LPILE using the modified SR p-y springs. A 6-foot diameter RC pile was modeled as an elastic beam with an elastic bending stiffness (EI) of 5.6e9 kips-in ${ }^{2}$ for the cracked concrete in the top 7.5 feet (cased) and 2.2e9 kips-in ${ }^{2}$ in the lower 19.5 feet (uncased). The EI of the cracked sections were estimated based on the sectional analysis and the expected magnitude of bending moments at the largest lateral load. The soil was modeled with API curves corresponding to sand with a friction angle of 38 degrees. The rock was modeled using SR curves (Vuggy Limestone) with the modification that is proposed in this study, i.e. residual strength equal to $20 \%$ pult. Input uniaxial compressive strength of $1298 \mathrm{psi}, 3140 \mathrm{psi}$, and $6409 \mathrm{psi}$ were used for heavily fractured rock $(\mathrm{RQD}=25 \%)$, fractured rock ( $\mathrm{RQD}=60 \%)$, and sound rock $(\mathrm{RQD}=100 \%)$, respectively. The input uniaxial strengths were calculated by multiplying the uniaxial strength of an intact rock with a reduction factor. The reduction factors were calculated using $\alpha^{2}$ where $\alpha$ is the joint modification factor from O'Neill and Reese (1999) for the three rock layers described above. The reduction factors that were used in this study were 0.2 and 0.49 for the heavily fractured rock $(\mathrm{RQD}=25 \%)$ and fractured rock $(\mathrm{RQD}=60 \%)$, respectively.

Comparison of Results. Figure 5 compares pile deflection and moment profiles between the lateral load test measurements, and the estimates using the p-y model. The values are extracted at the maximum lateral load exerted at pile head (1126 kips). The measured moment at the bottom of casing is larger than the estimated value (110,000 kip-in vs. 131,000 kip-in) and it drops sharply to 29,000 kip-in. This trend is not captured in the p-y model which in believed to be due to a more complex bending mechanism at the interface of cased vs. uncased sections. The estimated pile demands compare reasonably well with the measurements at other depths. 
Figure 6 shows the comparison of the lateral load-deformation response from the lateral load test and the p-y model. The load-deformation curve estimated from the p-y method matches the lateral load test results reasonably well. This favorable comparison implies that the initial stiffness of the SR p-y curves is reasonable. The mismatch between the load-deformation curves at small loads is likely due to the use of constant elastic modulus for concrete $(\mathrm{E})$ in the $\mathrm{p}$-y model. The comparison is expected to improve if a nonlinear moment-curvature behavior is modeled in the p-y model.

Despite the satisfactory comparison, the pile deflections at the rock-socket elevation did not exceed the $0.24 \%$ diameter to assess the hypothesis used in this study to modify the residual strength of the SR curve. Future lateral load tests are required to subjectively assess the validity of the assumption that the residual strength of the rock p-y curves should be smaller than the resistance of a heavily fractured rock mass.
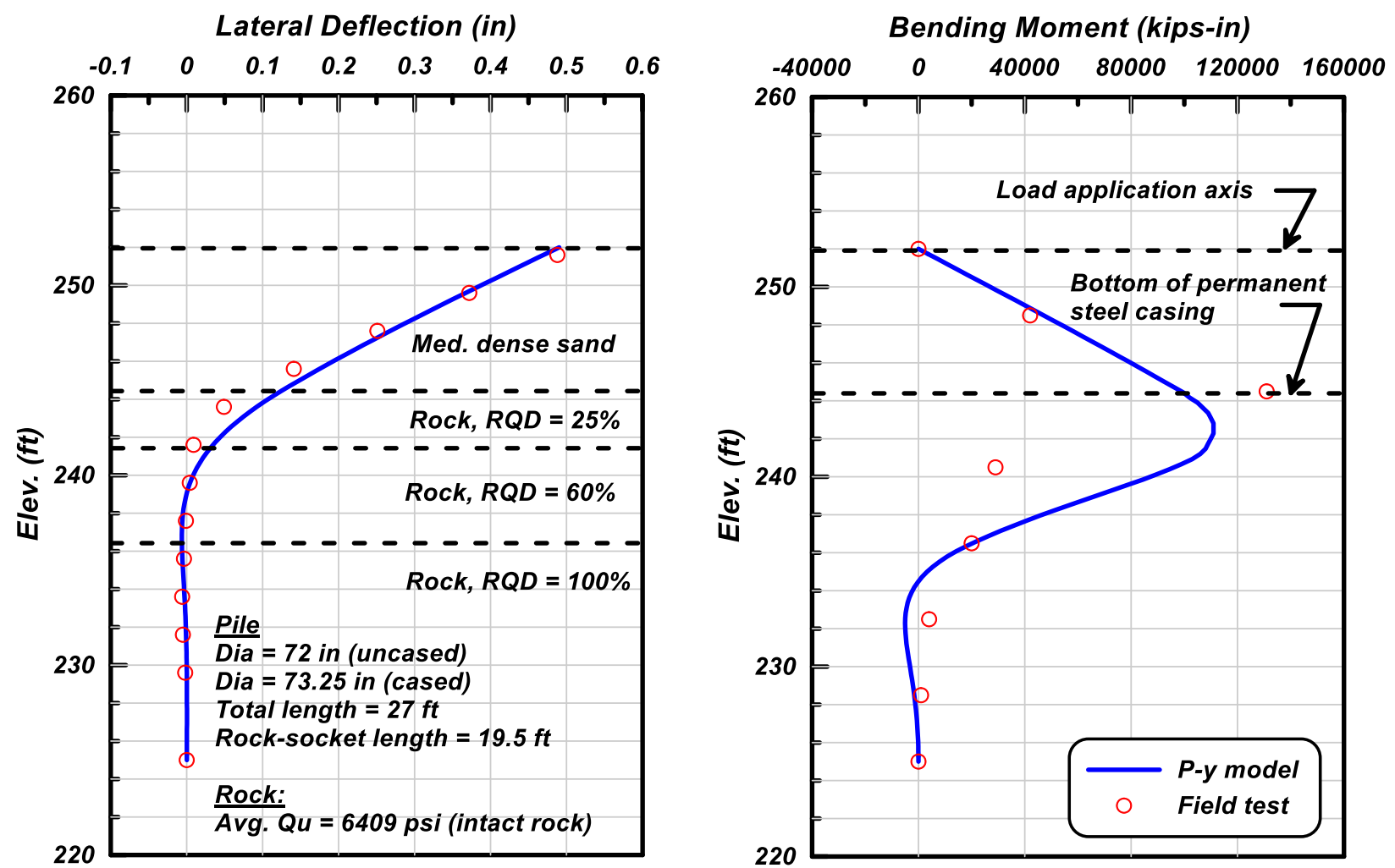

Figure 5. Comparison of pile demands measured in the lateral load test and estimated from a p-y model using the modified SR p-y curve. 


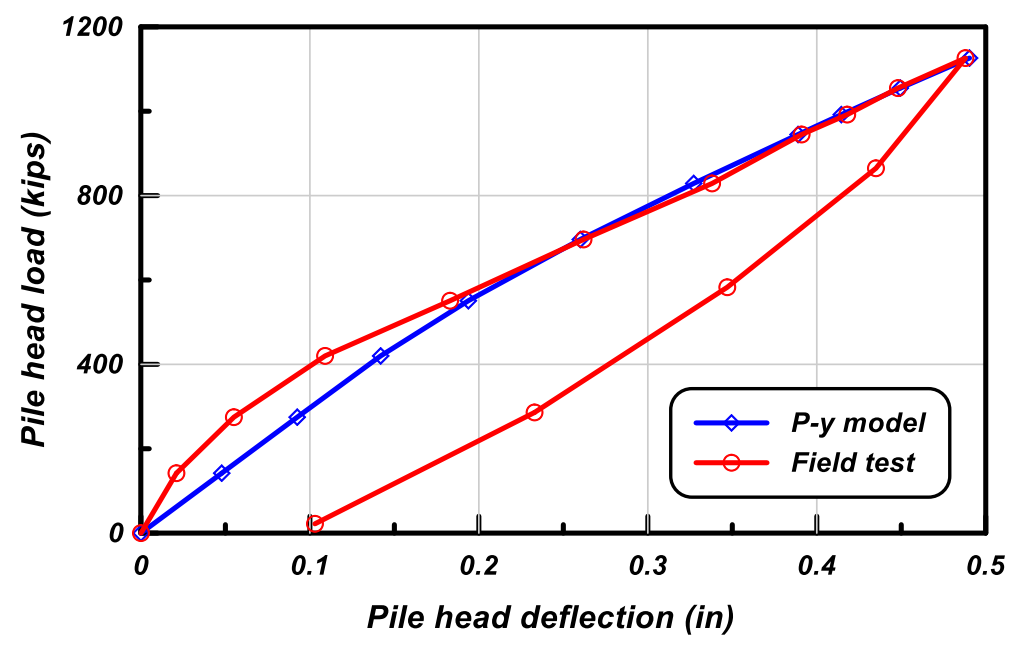

Figure 6. Comparison of pile head load-deflection between estimated results from p-y method and the measurements from the lateral load test

\section{BACK-CALCULATED PY CURVES IN ROCK FROM LATERAL LOAD TEST}

The lateral load test measurements were used to back-calculate p-y curves in rock. The bending moments were obtained from strain gauge measurements and pile deflections were recorded from an inclinometer embedded in the test shaft. The bending moments were approximated using the Smooth Cubic Spline method and were double differentiated to get the lateral rock pressure, $p$ (Haiderali and Madabhushi 2016; Brandenberg et al. 2010). The bending moment at pile head and tip were assumed zero. The pile head shear force (first derivative of moment) was assumed to be equal to the applied lateral load.

Figure 7 compares the back-calculated p-y curves from the lateral load test and the modified strong-rock (SR) curves. The back-calculated p-y curves were extracted at Elev. $241.5 \mathrm{ft}$ to 244.5 $\mathrm{ft}$ where the pile deflections were large enough to generate meaningful p-y curves. The rock RQD at these depths ranges between $25 \%$ to $60 \%$. The modified strong-rock (SR) curves plotted on Figure 7 were generated using a uniaxial compressive strength of $\mathrm{Qu}=1298 \mathrm{psi}$ and $3140 \mathrm{psi}$ for the heavily fractured rock $(\mathrm{RQD}=25 \%)$ and fractured rock $(\mathrm{RQD}=60 \%)$, respectively. The uniaxial compressive strengths of fractured rock mass were calculated by multiplying the uniaxial compressive strength of an intact rock (i.e. Qu=6409 psi) with reduction factors that were calculated from joint modification factors described earlier. The lateral load test was not pushed to large enough deflections to evaluate the modifications made to the residual strength of the SR curve. However, the comparison shows that the SR curves capture initial stiffness of the backcalculated p-y curves reasonably well. 


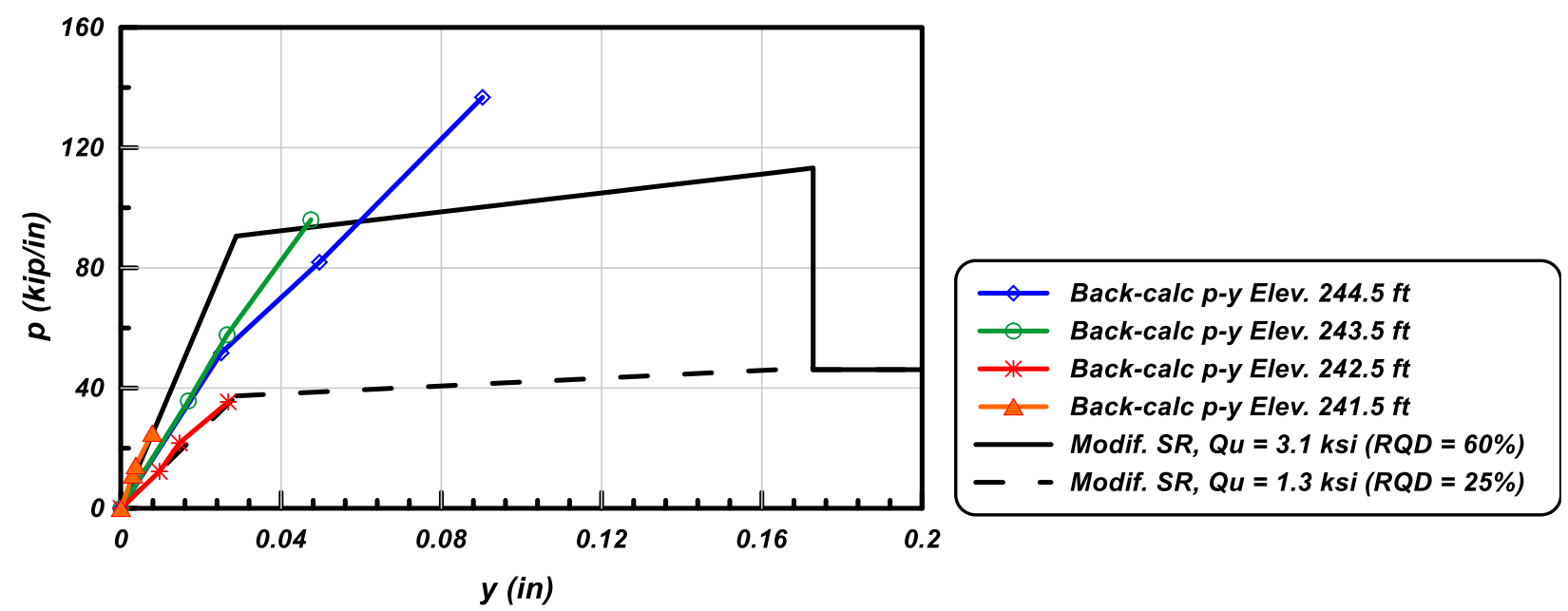

Figure 7. Comparison of p-y curves in rock socket back-calculated from the lateral load test and estimated using modified strong-rock (SR) curves.

\section{CONCLUSIONS}

The strong-rock (SR) p-y springs (also known as Vuggy Limestone) were modified by setting the residual strength at large deformations (greater than $0.0024 *$ diameter) to be equal to $20 \%$ of the ultimate lateral rock reaction ( $\mathrm{pult}_{\text {ult }}$. This modification was based on the assumption that the residual strength of strong rock (after cracking) should not be smaller than the resistance obtained from heavily fractured rock mass. This modification helped avoiding the progressive failure (unzipping) of SR p-y curves that resulted in unreasonably long rock-socket lengths. This could happen when the minimum required length for lateral stability is being analyzed following AASHTO (2014). The advantage of maintaining the original shape of the strong-rock (SR) curve is its favorable initial stiffness that falls within the range obtained from the weak-rock (WR) p-y curves and those proposed by Liang et al. (2009).

The modified SR curve was used to model a lateral load test on a 6-foot diameter reinforced concrete (RC) rock-socketed shaft. The pile demands estimated from the p-y model compared reasonably well with the test results. The pile head load-deflection curve compared well with the test results which showed the accuracy of the modified SR curve in estimating pile lateral stiffness. The p-y curves in rock were back-calculated from the lateral load test and compared against the modified SR curve. The comparison showed the advantage of using the modified SR curve in estimating the initial stiffness of $p-y$ response.

The lateral load tests do not often exceed deformations beyond the peak point on SR curves (i.e. $0.0024 *$ diameter). Additional lateral load tests are required where the piles are pushed further enough to assess the assumptions made in modifying the residual strength of the SR curves. 


\section{ACKNOWLEDGMENT}

Funding was provided by the Deep Foundations Institute (DFI). The author would like to thank Mr. Bill Billiet of Schnabel Engineering for providing the lateral load test data. The author also appreciates the comments by the project advisory board: Dr. Zia Zafir and Dr. John Turner. The idea of modifying the residual strength of SR p-y curves based on WR curves was developed based on discussions with Dr. Thaleia Travasarou and Mr. Jose Ugalde of Fugro. The author greatly appreciates their scholarly contribution.

\section{REFERENCES}

AASHTO (American Association of State Highway and Transportation Officials) (2014). "Guide Specifications for LRFD Seismic Bridge Design." Second Edition with 2014 Interim, AASHTO, Washington, D.C.

Brandenberg, S.J., Wilson, D.W., and Rashid, M.M. (2010). "A Weighted Residual Numerical Differentiation Algorithm Applied to Experimental Bending Moment Data.", Journal of Geotechnical and Geoenvironmental Engineering, 136(6), 854-863

Brown, D.A., Turner, J.P., and Castelli, R.J. (2010). "Drilled Shafts: Construction Procedures and LRFD Design Methods," Publication FHWA-NHI-10-016, FHWA, D.C., pp. 753

Deere, D. U. (1968). "Geological considerations." Rock mechanics in engineering practice, 1-20. Ensoft, (2014). "User's Technical Manual for LPile 2013"

Haiderali, A. E., and Madabhushi, G. (2016). "Evaluation of Curve Fitting Techniques in Deriving p--y Curves for Laterally Loaded Piles." Geotechnical and Geological Engineering, Springer, 34(5), 1453-1473.

Hoek, E. (2001). "Rock Mass Properties for Underground Mines," Underground Mining Methods: Engineering Fundamentals and International Case Studies," Society for Mining, Metallurgy, and Exploration.

Liang, R., Yang, K., and Nusairat, J., (2009). "p-y Criterion for Rock Mass," Journal of Geotechnical and Geoenvironmental Engineering, Vol. 135, No. 1, pp. 26-36.

Marinos, P., and Hoek, E., 2000. "GSI - A Geologically Friendly Tool for Rock Mass Strength Estimation," Proceedings, GeoEngineering 2000 Conference, Melbourne, pp.1,422-1,442

O'Neill, M. W. and L. C. Reese. (I999). "Drilled Shafts: Construction Procedures and Design Methods," FHWA-IF-99-025, Federal Highway Administration, U.S. Department of Transportation, Washington, DC.

Reese, L. C., (1997). "Analysis of Piles in Weak Rock," Journal of the Geotechnical and Geoenvironmental Engineering Division, ASCE, pp. 1010-1017.

Schnabel Engineering Consultants, Inc. (2014). "Load Test Report, Aerial Guideway Load Test Program, Dulles Corridor Metrorail Project - Phase 2 Package A, Loudon and Fairfax County, Virginia"

Turner, J. P. (2006). "NCHRP Synthesis 360: Rock-Socketed Shafts for Highway Structure Foundations." Transportation Research Board, National Research Council, DC, 148 pp. 